\section{Pharmacodynamics of vecuronium in patients with and without renal failure: a meta-analysis}

C. Beauvoir MD, ${ }^{*}$ P. Peray MD, $\dagger$ J.P. Daures MD, $\dagger$ J.L. Peschaud MD, ${ }^{*}$ F. D'Athis MD*
Eight trials comparing the effects of vecuronium in patients with either normal renal function or renal failure were subjected to a meta-analysis. Vecuronium doses were similar in the different trials, identical in the two patient groups of any given trial, and ranged from 0.05 to $0.14 \mathrm{mg} \cdot \mathrm{kg}^{-1}$. Neuromuscular blockade was assessed by TOF or single twitch stimulation, and recorded by either mechanomyography or electromyography. Indices of blockade included onset time (from injection to maximal twitch depression), duration of action (from injection to recovery to $25 \%$ of control twitch) and $25-75 \%$ recovery index. Statistical analysis used Hedges method: effect size and variance were calculated for each relevant outcome, then the global effect size was estimated by pooling the effect sizes of each trial. Three separate meta-analyses were conducted. No differences were found either in onset time, or in recovery index between the two groups, whereas the duration of action was longer in the renal failure group. It is concluded that renal function is likely involved in the pharmacokinetic parameters of vecuronium.

Huit études comparant les paramètres pharmacodynamiques $d u$ vécuronium dans deux populations, une à fonction rénale normale et l'autre en insuffisance rénale terminale, sont incluses dans une méta-analyse. Les posologies de vécuronium sont similaires entre les études, et identiques dans les deux populations de chaque étude. Le mode de stimulation est le train de quatre ou le single twitch, le monitorage est réalisé par mécanographie ou électromyographie. Les critères de jugement sont le délai

\section{Key words}

COMPLICATIONS: renal failure;

NEUROMUSCULAR RELAXANTS: vecuronium; STATISTICS.

From the *Département d'Anesthésie-Réanimation A, †Département d'Information Médicale, Hôpital Lapeyronie, 34059 Montpellier Cedex - France.

Address correspondence to: Dr. C. Beauvoir.

Accepted for publication 26th March, 1993 d'action (de linjection à la dépression maximale du twitch), la durée d'action (de linjection à la récupération de $25 \%$ du twitch) et lindex de récupération 25-75. Les comparaisons statistiques utilisent la méthode de Hedges. Trois méta-analyses différentes sont réalisées, une par critère de jugement : aucune. différence significative n'est mise en évidence entre les deux populations, ni pour le délai d'action, ni pour lindex de récupération. Par contre, la durée d'action est significativement allongée dans la population en insuffisance rénale. La fonction rénale joue donc probablement un rôle dans la pharmacocinétique du vécuronium.

The influence of renal failure on the pharmacodynamics and pharmacokinetics of vecuronium has not been clearly established. Initially Fahey ${ }^{1}$ and Hunter ${ }^{2}$ demonstrated that neither the duration of neuromuscular blockade nor the pharmacokinetics of vecuronium were affected by renal dysfunction. Meistelman ${ }^{3}$ and Bencini ${ }^{4}$ also found no prolongation of blockade, in spite of a tendency towards an increased elimination half-life. Lynam ${ }^{5}$ affirmed a longer duration of action and an increased elimination half-life in patients with end-stage renal failure (RF); the volume of distribution remained unchanged. Finally, Peschaud's works ${ }^{6}$ confirmed the blockade prolongation in RF patients undergoing renal transplantation.

The present study was designed to compare pharmacodynamic variables of vecuronium in RF patients with those with normal renal function (NRF). Meta-analysis, a statistical method of combining existing research results, was employed in this effort to clarify the controversy. Though widely used in epidemiology ${ }^{7-10}$ this method is comparatively new to anaesthesia. This technique can be of great interest when interpreting existing research data concerning the same problem. Some studies do not achieve statistical significance due to lack of power, that is, an insufficient number of patients. By regrouping similar studies, an adequate sample size can be obtained and a previously undetected significance revealed. Furthermore, when one study presents results which differ from the others, regrouping the studies may detect in which direction statistical significance can be found. 


\section{Methods}

\section{Reports and publications}

The eight studies analysed were procured by accessing the Medline Data bank, inspecting the bibliography of each publication, and by direct inquiry with the anaesthesia staff of the DAR A (Montpellier) in search of unpublished articles. The only data included from abstracts or conference presentations concerned Peschaud's work. As meta-analysis should present an exhaustive compilation of available data we included this unpublished study. ${ }^{9}$

\section{Variables considered in each study}

The variables were selected in keeping with the recommendations of Chalmers, ${ }^{12}$ Poynard, ${ }^{13}$ Gerbarg $^{14}$ and Pignon. ${ }^{15}$ They were classed into two groups according to their importance in the evaluation of the quality of the research design, and thereby the meta-analysis.

Those variables considered fundamental included: patients's age and sex, number of groups, number of patients in each group, criteria for inclusion/non-inclusion in each group, vecuronium doses, principal and accessory judgement criteria, techniques used to set the judgement criteria, motives for and number of exclusions, group comparability, results and related significance of the two groups. Those considered of limited interest included: countries where studies using similar protocols were undertaken, informed patients consent, ethics committee approval. The principal judgement criteria were those considered most relevant to the aim of the meta-analysis. They were chosen among those most frequently cited by the various authors. The other criteria were considered as accessory. In this work, the multiplicity of the variables used to measure the pharmacodynamics of vecuronium led us to retain only the three encountered in the majority of the studies:

- onset time (min): time from first injection to maximal twitch depression.

- duration of action or DUR 25 ( $\mathrm{min}$ ): time from first injection to recovery of $25 \%$ of control twitch. In Hunter's study, DUR 25 was replaced by DUR 10.

- 25-75 recovery index.

Other parameters such as DUR 90 and $\mathrm{T}_{4}$ ratio $75 \%$ were not retained, as they were not systematically measured.

\section{Potential bias control: studies selection}

In order to maintain a comparable quality level in both the protocols and the variables, only studies meeting all three of the following criteria were retained as eligible:

- vecuronium doses had to be similar in the different trials, and identical in the two patient groups of a given trial. The doses ranged from $0.05 \mathrm{mg} \cdot \mathrm{kg}^{-1}$ to 0.14 $\mathrm{mg} \cdot \mathrm{kg}^{-1}$, with or without reinjection, as the collected variables concerned only the first injection. We did not take into account the studies using cumulative dose technique. ${ }^{16-18}$

- neuromuscular function was monitored by either mechanomyography (MMG) or electromyography (EMMG).

- the ulnar nerve was stimulated supramaximally using either train-of-four or single twitch mode.

Randomization was not retained as a criterion in this study, as the comparison of two subject groups, one with renal failure and one without, does not require it. The type of anaesthetic used was not retained, as both patient groups of a given trial received the same agents. As such, the effect on the measured criteria can be considered to be the same.

All studies using variable vecuronium doses in a given trial or using pharmacodynamic judgement criteria other than the three we retained were considered to be noneligible.

\section{Trial grouping}

As not all pharmacodynamic variables were systematically recorded in every study, the trials were grouped according to variable availability.

\section{Statistical analysis}

The first step was to calculate the effect size and the variance for each relevant outcome. ${ }^{19}$ The effect size measures the mean difference between the two groups of a given trial, divided by the standard deviation. The second step involved measuring the study heterogeneity. ${ }^{20}$ The term heterogeneity refers to a situation where a variable mean value derived from one study greatly differs from the global mean value derived from the other studies. In such circumstances, special statistical methods must be applied: the width of the confidence interval was increased and the statistical test was penalized. The third step involved calculating the global effect size by pooling the effect sizes of each trial.

\section{Results}

\section{Included trials}

From the eight studies identified, six were included in the meta-analysis. This represents seven trials, as Bencini's study consists of two sections: one receiving doses of $0.05 \mathrm{mg} \cdot \mathrm{kg}^{-1}$ and one receiving $0.1 \mathrm{mg} \cdot \mathrm{kg}^{-1}$. Hunter's trial was only partially exploited, as some patients received atracurium.

Two studies were excluded. In Bevan's study, ${ }^{21}$ randomized blocks of incremental doses ranging from 0.01 
TABLE I Variables examined in each trial

\begin{tabular}{|c|c|c|c|c|c|c|c|c|}
\hline \multirow[b]{2}{*}{ Author } & \multirow[b]{2}{*}{ Year } & \multicolumn{2}{|c|}{ Mean age (SD) yr } & \multirow{2}{*}{$\begin{array}{l}\text { Inclusion criseria } \\
R F\end{array}$} & \multirow{2}{*}{$\begin{array}{l}\text { Inclusion criteria } \\
N R F\end{array}$} & \multirow{2}{*}{$\begin{array}{l}\text { Dose } \\
\mathrm{mg} \cdot \mathrm{kg}^{-1}\end{array}$} & \multirow[b]{2}{*}{ Monitoring } & \multirow[b]{2}{*}{ Anaesthesia } \\
\hline & & $N R F$ & $R F$ & & & & & \\
\hline \multirow[t]{3}{*}{ Bencini } & 1986 & \multirow{3}{*}{\multicolumn{2}{|c|}{$20^{*}-50 \dagger$}} & $\begin{array}{l}\text { Clearance } \\
<5 \mathrm{ml} \cdot \mathrm{mn}^{-1}\end{array}$ & ASA I or II & 0.05 & $\begin{array}{l}\text { Single } \\
\text { twitch }\end{array}$ & $\begin{array}{l}\text { Thiopentone } \\
\text { Fentanyl }\end{array}$ \\
\hline & & & & $\begin{array}{l}\text { Haemodialysis before } \\
\text { AV fistula }\end{array}$ & & & & \\
\hline & & & & $\begin{array}{l}\text { No renal } \\
\text { transplantation }\end{array}$ & & 0.1 & MMG & $\begin{array}{l}\text { Halothane } \\
0.5 \%\end{array}$ \\
\hline Fahey & 1981 & \multirow{2}{*}{\multicolumn{2}{|c|}{$20^{*}-55 \dagger$}} & $\begin{array}{l}\text { AV fistula } \\
\text { Haemodialysis before }\end{array}$ & $\begin{array}{l}\text { Normal renal } \\
\text { function }\end{array}$ & 0.14 & $\begin{array}{l}\text { Single } \\
\text { twitch }\end{array}$ & Thiopentone \\
\hline & & & & & & & MMG & $0.4-1 \%$ \\
\hline Hunter & 1984 & 50 & 44 & $\begin{array}{l}\text { Clearance } \\
<2 \mathrm{ml} \cdot \mathrm{mn}^{-1}\end{array}$ & ASA I or II & 0.1 & $\begin{array}{l}\text { Train-of }-4 \\
\text { MMG }\end{array}$ & $\begin{array}{l}\text { Thiopentone } \\
\text { Fentanyl }\end{array}$ \\
\hline Lynam & 1988 & - & - & $\begin{array}{l}\text { Haemodialysis } \\
\text { just before } \\
\text { transplantation }\end{array}$ & ASA I or II & 0.1 & $\begin{array}{l}\text { Single } \\
\text { twitch } \\
\text { MMG }\end{array}$ & $\begin{array}{l}\text { Thiopentone } \\
\text { Isoflurane }\end{array}$ \\
\hline Meistelman & 1986 & $\begin{array}{l}43.4 \\
(15.7)\end{array}$ & $\begin{array}{l}44.7 \\
(16.4)\end{array}$ & AV fistula & $\begin{array}{l}\text { Créatinine } \\
<100 \mu \mathrm{g} \cdot \mathrm{ml}^{-1}\end{array}$ & 0.05 & $\begin{array}{l}\text { Single } \\
\text { twitch } \\
\text { MMG }\end{array}$ & $\begin{array}{l}\text { Thiopentone } \\
\text { Fentanyl }\end{array}$ \\
\hline Peschaud & 1990 & $\begin{array}{l}44.2 \\
(13)\end{array}$ & $\begin{array}{l}46.8 \\
(11.7)\end{array}$ & Transplantation & $\begin{array}{l}\text { ASA I or II } \\
\text { scheduled urological } \\
\text { surgery }\end{array}$ & 0.1 & $\begin{array}{l}\text { Train-of-4 } \\
\text { EMG }\end{array}$ & $\begin{array}{l}\text { Propofol } \\
\text { Fentanyl }\end{array}$ \\
\hline
\end{tabular}

*Minimum. †Maximum.

TABLE II Variables examined in each trial (continued)

\begin{tabular}{|c|c|c|c|c|c|}
\hline Author & $\begin{array}{l}\text { Number of } \\
\text { patients included } \\
\text { NRF }\end{array}$ & $\begin{array}{l}\text { Number of } \\
\text { patients included } \\
R F\end{array}$ & $\begin{array}{l}\text { Number of } \\
\text { patients excluded } \\
\text { NRF }\end{array}$ & $\begin{array}{l}\text { Number of } \\
\text { patients excluded } \\
\text { RF }\end{array}$ & $\begin{array}{l}\text { Exclusion } \\
\text { criteria }\end{array}$ \\
\hline Bencini 0,05 & 6 & 8 & 1 & 3 & no \\
\hline Bencini 0,1 & 7 & 8 & 4 & 4 & no \\
\hline Fahey & 4 & 5 & 0 & 1 & yes \\
\hline Hunter & 21 & 21 & $2^{*}$ & $4^{*}$ & yes \\
\hline Lynam & 7 & 12 & 0 & $5^{*}$ & yes \\
\hline Meistelman & 10 & 10 & 0 & 0 & - \\
\hline Peschaud & 11 & 11 & 0 & 0 & - \\
\hline
\end{tabular}

* Partial exclusion: some variables could not be measured.

$\mathrm{mg} \cdot \mathrm{kg}^{-1}$ to $0.06 \mathrm{mg} \cdot \mathrm{kg}^{-1}$ were used to investigate the dose-response relationship. At least two subjects received a given dose, and the specific pharmacodynamic results for each dose were not expressed. Orko's study ${ }^{22}$ consisted of administering a bolus with subsequent reinjections until maximal muscle relaxation was obtained.

\section{Evaluation of the variables examined in each trial} (Tables I and II)

All the patients included in the RF group were either transplant candidates, or at least undergoing haemodialysis. In most of the trials, the patients of the NRF group corresponded either to one of the first two categories of the ASA classification, or its equivalent.
In five of the studies, some patients were excluded from the analysis. No explanation was provided for the exclusions from Bencini's study, but the number excluded was approximately balanced between each of the two groups of the trial. These exclusions can, therefore, be disregarded. In the other three trials, explanations were provided. One of Fahey's RF patients required block reversal before the anticipated spontaneous recovery. The onset of action was measured for all of Hunter's patients, and was defined as the time to maximal depression or to disappearance of the twitch. In 4/21 RF and in 2/ 21 NRF patients, the twitch was never completely abolished. As such, Hunter decided to exclude these six patients when calculating the DUR 25. Similarly, the onset 
TABLE III Individual results of the trials: onset time

\begin{tabular}{|c|c|c|c|c|c|c|c|c|}
\hline \multirow[b]{2}{*}{ Author } & \multicolumn{2}{|c|}{ Number of patients } & \multirow{2}{*}{$\begin{array}{l}\text { Dose } \\
m g \cdot k g^{-1}\end{array}$} & \multicolumn{2}{|c|}{ Onset time $\min (S D)$} & \multirow{2}{*}{$\begin{array}{l}\text { Onset time } \\
\text { difference }\end{array}$} & \multirow{2}{*}{$\begin{array}{l}95 \% \mathrm{Cl} \text { of } \\
\text { the difference }\end{array}$} & \multirow[b]{2}{*}{ Significance } \\
\hline & $N R F$ & $R F$ & & $N R F$ & $R F$ & & & \\
\hline \multirow[t]{2}{*}{ Bencini } & 5 & 5 & 0.05 & $5.9(2.5)$ & $5.2(2.3)$ & 0.7 & $(-2.8 ; 4.2)$ & NS \\
\hline & 3 & 4 & 0.1 & $2.9(0.3)$ & $5.1(1.2)$ & -2.2 & $(-4.06 ;-0.34)$ & $P<0.05$ \\
\hline Fahey & 4 & 4 & 0.14 & $2.1(0.6)$ & $1.80(0.7)$ & 0.3 & $(-0.83 ; 1.43)$ & NS \\
\hline Hunter & 21 & 21 & 0.1 & $2.95(2.6)$ & $3.18(2.65)$ & -0.23 & $(-1.83 ; 1.37)$ & NS \\
\hline Lynam & 7 & 12 & 0.1 & $1.8(0.6)$ & $1.9(0.8)$ & -0.1 & $(-0.84 ; 0.64)$ & NS \\
\hline Meistelman & 10 & 10 & 0.05 & $5.2(6.3)$ & $5.9(6)$ & -0.7 & $(-6.5 ; 5.1)$ & NS \\
\hline Peschaud & 11 & 11 & 0.1 & $2.43(0.67)$ & $2.32(0.8)$ & -0.11 & $(-0.55 ; 0.77)$ & NS \\
\hline
\end{tabular}

TABLE IV Individual results of the trials: DUR 25

\begin{tabular}{|c|c|c|c|c|c|c|c|c|}
\hline \multirow[b]{2}{*}{ Author } & \multicolumn{2}{|c|}{ Number of patients } & \multirow{2}{*}{$\begin{array}{l}\text { Dose } \\
m g \cdot k g^{-1}\end{array}$} & \multicolumn{2}{|c|}{$D U R 25 \min (S D)$} & \multirow{2}{*}{$\begin{array}{l}\text { Difference of } \\
\text { DUR } 25\end{array}$} & \multirow{2}{*}{$\begin{array}{l}95 \% \mathrm{Cl} \text { of } \\
\text { the difference }\end{array}$} & \multirow[b]{2}{*}{ Significance } \\
\hline & $N R F$ & $R F$ & & $N R F$ & $R F$ & & & \\
\hline \multirow[t]{2}{*}{ Bencini } & 5 & 5 & 0.05 & $18.1(6.6)$ & $22.3(7)$ & -4.2 & $(-14.12 ; 5.72)$ & NS \\
\hline & 3 & 4 & 0.1 & $23.6(9.3)$ & $29.6(4.2)$ & -6 & $(-19.2 ; 7.2)$ & NS \\
\hline Hunter & 19 & 17 & 0.1 & $27(8)$ & $35(28)$ & -8 & $(-21.15 ; 5.15)$ & NS \\
\hline Lynam & 7 & 7 & 0.1 & $54.1(25.2)$ & $98.6(37.7)$ & -44.5 & $(-81.85 ;-7.15)$ & $P<0.05$ \\
\hline Peschaud & 11 & 11 & 0.1 & $35.3(5.3)$ & $46.5(11)$ & -11.2 & $(-18.87 ;-3.53)$ & $P<0.01$ \\
\hline
\end{tabular}

TABLE V Individual results of the trials: $25-75$ recovery index

\begin{tabular}{|c|c|c|c|c|c|c|c|c|}
\hline \multirow[b]{2}{*}{ Author } & \multicolumn{2}{|c|}{ Number of patients } & \multirow{2}{*}{$\begin{array}{l}\text { Dose } \\
m g \cdot k g^{-1}\end{array}$} & \multicolumn{2}{|c|}{$25-75$ index $\min (S D)$} & \multirow{2}{*}{$\begin{array}{l}\text { Difference of } \\
25-75 \text { index } \\
\text { (min) }\end{array}$} & \multirow{2}{*}{$\begin{array}{l}95 \% \mathrm{Cl} \text { of } \\
\text { the difference }\end{array}$} & \multirow[b]{2}{*}{ Significance } \\
\hline & $N R F$ & $R F$ & & $N R F$ & $R F$ & & & \\
\hline \multirow[t]{2}{*}{ Bencini } & 5 & 5 & 0.05 & $7.2(3.1)$ & $10.5(3.6)$ & -3.3 & $(-8.2 ; 1.6)$ & NS \\
\hline & 3 & 4 & 0.1 & $8.8(1)$ & $17.2(1)$ & -8.4 & $(-10.36 ;-6.44)$ & $P<0.05$ \\
\hline Meistelman & 10 & 10 & 0.05 & $7.2(9.5)$ & $10.5(11.4)$ & -3.3 & $(-13.2 ; 6.6)$ & NS* \\
\hline Peschaud & 11 & 11 & 0.1 & $13.9(4.6)$ & $48.7(32.9)$ & -34.8 & $(-55.69 ;-13.91)$ & $P<0.01$ \\
\hline
\end{tabular}

* Recalculated values based on the article data.

of action was measured for all of Lynam's patients; however, the DUR 25 was not in 5/12 RF patients.

Informed consent was obtained for all patients, except those included in Hunter's and Peschaud's studies for which no information was available. Ethics Committee approval was required in all studies.

The number of patients required to achieve statistical significance and the study power were never calculated by the different authors.

The patients included in the two groups of a given trial were comparable with respect to the principal variables (age, sex, weight) except in Bencini's, Fahey's and Lynam's studies, where no comparisons were performed.

\section{Individual results of the trials}

The mean differences and the $95 \%$ confidence intervals concerning the three pharmacodynamic criteria retained in the meta-analysis are represented in Tables III, IV and
$V$. If the two means of the studied criteria were not statistically different, their difference was therefore zero, and this zero was included in the confidence interval. As such, no significant difference was observed between the two groups concerning this criteria.

In only one of the seven trials (Bencini $0.1 \mathrm{mg} \cdot \mathrm{kg}^{-1}$ ), was the onset of action found to be longer in RF patients. In two out of five trials (Lynam, Peschaud) the DUR 25 was found to be longer in RF patients. In two out of four trials (Bencini $0.1 \mathrm{mg} \cdot \mathrm{kg}^{-1}$, Peschaud), the $25-75$ index was found to be longer in RF patients.

Meta-analysis results (Table VI)

Three separate meta-analyses were conducted using only different trials, but also different patients selected from each trial in accordance with judgement criteria availability. For a given patient, not all three judgement criteria were necessarily available. As such, the number of pa- 
TABLE VI Meta-analysis results

\begin{tabular}{|c|c|c|c|c|c|c|c|c|}
\hline \multirow[b]{2}{*}{ Judgement criteria } & \multicolumn{2}{|c|}{ Number of patients } & \multicolumn{2}{|l|}{ Mean } & \multirow[b]{2}{*}{ Effect size } & \multirow[b]{2}{*}{ Heterogeneity } & \multirow[b]{2}{*}{$95 \%$ Cl effect size } & \multirow[b]{2}{*}{ Significance } \\
\hline & $N R F$ & $R F$ & $N R F$ & $R F$ & & & & \\
\hline Onset time & 61 & 67 & 3.33 & 3.63 & -0.122 & no & $(-0.23 ; 0.47)$ & NS \\
\hline DUR 25 & 45 & 44 & 31.6 & 46.4 & -0.84 & no & $(-1.43 ;-0.25)$ & $P<0.001$ \\
\hline Index 25-75 & 29 & 30 & 9.3 & 21.7 & -1.88 & yes & $(-7.43 ; 3.66)$ & NS \\
\hline
\end{tabular}

tients involved in each meta-analysis is different. For example, in Hunter's study, two groups of 21 patients were available for onset time analysis, two groups consisting of 19 and 17 patients respectively for the DUR 25, and no one for the 25-75 recovery index.

IST META-ANALYSIS: ONSET TIME ( $n=7$ TRIALS)

This meta-analysis was based on 61 NRF patients and 67 RF patients. The homogeneity verification demonstrated no differences, so that the results of the trials can be considered to be homogenous. The effect size dw was 0.122 and the $95 \%$ confidence interval was $(-0.23 ; 0.47)$ (NS).

2ND META-ANALYSIS: DUR 25 ( $n=5$ TRIALS)

This meta-analysis was based on 45 NRF patients and 44 RF patients. The homogeneity check demonstrated no differences, so that the results of the trials can be considered to be homogenous. The effect size dw was -0.84 and the $95 \%$ confidence interval was $(-1.43$; $-0.25)(P<0.001)$.

\section{RD META-ANALYSIS: $25-75 \%$ RECOVERY INDEX $(n=$ 4 TRIALS)}

This meta-analysis was based on 29 NRF patients and 30 RF patients. The homogeneity check demonstrated differences, so that the results of the trials can be considered to be heterogenous. This must be taken into account when calculating the effect size, dw was -1.88 , and the $95 \%$ confidence interval was $-7.43 ; 3.66$ (NS).

Finally, only one variable, the DUR 25 , was found to be different in the two populations. The difference between the two group's mean values was approximately 14 minutes.

To eliminate Beta errors, the power of the metaanalysis based on the non-significant variables was calculated; that is the $25-75$ recovery index (power $=1$ - $\beta$ ) had a power of $86 \%$, which was sufficient.

\section{Discussion}

In elaborating a meta-analysis, one is confronted with problems arising from the different methods used in the different trials: patient inclusion criteria and above all, judgement criteria. Even when limiting oneself strictly to pharmacodynamics, the evaluation remains heterogenous, and depends on both the research team and the data of execution.

Though the NRF category was never clearly defined by measurement of serum creatinine concentration, as all the subjects were ASA 1 or 2, advanced pathology was excluded. The RF subjects were all in the terminal phase and were undergoing haemodialysis. In most of the studies, haemodialysis was specified to have been performed within $24 \mathrm{hr}$ of surgery.

Anaesthesia was induced with either thiopentone or propofol and continued with either fentanyl or a halogenated agent (halothane or isoflurane) or both. According to Agoston, ${ }^{23}$ potentiation of the muscle relaxants effects by halogenated agents has been shown in some experimental studies. However, under usual clinical conditions, no potentiation of the effects of vecuronium was observed. Starsnic ${ }^{24}$ did not find any difference in the onset or recovery of the vecuronium block when increasing isoflurane concentrations. As the same concentration of the same halogen was administered to both groups of a given study, the effect was not relevant to the analysis.

Ulnar nerve stimulation was by single twitch stimulation in four studies and TOF stimulation in two studies. The height of the first response TOF stimulation provides the same information as the single twitch stimulation as $0.1 \mathrm{~Hz},{ }^{17}$ provided that the TOF are separated by $10-12$ $\mathrm{sec}$ to allow recovery of the neuromuscular junction between trains. ${ }^{28}$ However, Cooper, ${ }^{29}$ when testing rocuronium, found that the degree of block attained was greater, and the time taken to attain it was shorter when using TOF stimulation. Adductor pollicis muscle contraction was recorded by $M M G$ in five studies and EMG in one study. The EMG is a more recent development and is more manageable during anaesthesia. According to some authors, ${ }^{30}$ EMG underestimates the degree of muscle relaxation and overestimates the recovery, while others ${ }^{31-34}$ found a good correlation between the two techniques.

The different methods applied may explain the variations seen in the absolute values obtained by the different authors. However, as the protocols applied to the two patient groups in each trial were identical, meta- 
nalysis comparing the variations between these two populations is legitimate.

Can our findings, i.e., an increased duration of action and an unmodified onset time in RF patients, be explained? The onset time depends in part on the cardiac output, which is normally elevated in RF patients due to the presence of an arterio-venous fistula. However, this variation may not be large enough to affect the onset time. On the other hand, it is difficult to explain how the duration could be prolonged, while the recovery index was not modified. The answer may lie in the statistical methodology as the third meta-analysis, concerning recovery index, included only three studies, but was calculated to have a good power of $86 \%$. However, its results are considered to be heterogenous, and therefore the statistical test was penalized. This could explain why a difference was not found between the recovery index of the two groups.

In some of the studies retained for this meta-analysis, ${ }^{2,6}$ and in others, ${ }^{17,20,24-27}$ the authors used a multiple bolus technique to investigate vecuronium pharmacology. Hunter ${ }^{6}$ found no tendency towards accumulation in 25 NRF or RF patients. Fahey ${ }^{25}$ and Fisher, ${ }^{26}$ found a slight increase in the block duration with repetitive doses in NRF patients. In RF patients, Bevan ${ }^{20}$ showed that cumulative effects were seen when repeated doses were injected during the distribution phase of the previous dose. Lepage $^{17}$ indicated accumulation of vecuronium in end stage renal failure, after the fourth maintenance dose. Due to the wide range of doses and dosing intervals used, these studies were difficult to compare. If, however, prolongation of action in RF patients could be shown for the first dose, "a fortiori" this prolongation should exist for the repeat doses. Whether this accumulation was the result of decreased degradation, decreased elimination, or redistribution, could be elucidated by further comparing pharmacokinetic data. 1,3,5,23,26,35 Due to multiple dosing techniques (gas chromatography, HPLC, fluorometry) and different sampling procedures, this study could not be carried out.

This meta-analysis demonstrated only one difference $(P<0.001)$ : an increased duration of action of vecuronium in RF patients. Because only a small number of studies was involved, the robustness of this result was assessed. ${ }^{36}$ As the duration of action was the only significant variable, the calculation was based on this. We found that three additional non-significant studies would be necessary to invalidate our results. As only six studies were found in the literature, it is unlikely that three nonsignificant findings were missed. Therefore, the result can be considered to be robust, and be retained.

In conclusion, the duration of action of vecuronium was found by meta-analysis to be prolonged in patients with terminal renal failure. Additional pharmacokinetic data are needed to clarify these results.

\section{References}

1 Fahey MR, Morris RB, Miller RD, Nguyen $T L$, Upton $R A$. Pharmacokinetics of ORG NC 45 (Norcuron) in patients with and without renal failure. Br J Anaesth 1981; 53: 1049-53.

2 Hunter JM, Jones RS, Utting JE. Comparison of vecuronium, atracurium and tubocurarine in normal patients and in patients with no renal function. $\mathrm{Br} \mathrm{J}$ Anaesth 1984; 56: 941-51.

3 Meistelman C, Lienhart A, Leveque C, Bitker MO, Pigot $B$, Viars $P$. Pharmacology of vecuronium in patients with end-stage renal failure. Eur J Anaesthesiol 1986; 3: 153-8.

4 Bencini $A$, Scaf $A H J$, Sohn YJ, et al. Disposition and urinary excretion of vecuronium bromide in anesthetized patients with normal renal function or renal failure. Anesth Analg 1986; 65: 245-51.

5 Lynam DP, Cronnelly $R$, Castagnoli $K P$, et al. The pharmacodynamics and pharmacokinetics of vecuronium in patients anesthetized with isoflurane with normal renal function or with renal failure. Anesthesiology 1988; 69: 227-39.

6 Peschaud JL, Kienlen J, Rey G, et al. Pharmacodynamics of vecuronium in patients with and without chronic renal failure. Anesthesiology 1990; 73: 3A, A916.

7 Daures JP, Schved JF, Momas I, Gril JC, Azoulay P, Gremy $F$. Méta-analyse sur les essais randomisés comparant les résultats des héparines de bas poids moléculaire à ceux des héparines fractionnées dans la prévention des thromboses veineuses profondes. Rev Epidemiol Santé Publique 1989; 37: 363-9.

8 Daures J-P, Peray P, Bories P, et al. Place de la corticothérapie dans le traitement des hépatites alcooliques aiguës résultats d'une méta-analyse. Gastroenterol Clin Biol 1991; 15: 223-8.

9 Himel H, Liberati A, Gelber RD, Chalmers TC. Adjuvant chemotherapy for breast cancer: a pooled estimate based on published randomized control trials. JAMA 1986; 9 : 1148-59.

10 Padgett D, Mumford E, Hynes M, Carter R. Metaanalysis of the effects of educational and psychosocial interventions on management of diabetes mellitus. J Clin Epidemiol 1988; 41: 1007-30.

11 Pace NL. Prevention of succinylcholine myalgias: a metaanalysis. Anesth Analg 1990; 70: 477-83.

12 Chalmers TC, Levin H, Sacks HS, Reitman D, Berrier J, Nagalingam $R$. Meta-analysis of clinical trials as a scientific discipline. (I): Control of bias and comparison with large co-operative trials. Stat Med 1987; 6: 315-25.

13 Poynard $T$. Evaluation de la qualité méthodologique des essais thérapeutiques randomisés. Presse Med 1988; 17 : 315-8. 
14 Gerbarg ZB, Horwitz RI. Resolving conflicting clinical trials: guidelines for meta-analysis. J Clin Epidemiol 1988; 41: 503-9.

15 Pignon JP, Poynard T. Méta-analyse des essais thérapeutiques. Gastroenterol Clin Biol 1991; 15: 229-38.

16 Gramstad L. Atracurium, vecuronium and pancuronium in end-stage renal failure. Br J Anaesth 1987; 59: 995-1003.

17 Lepage JY, Malinge M, Cozian A, Pinaud M, Blanloeil Y, Souron $R$. Vecuronium and atracurium in patients with end-stage renal failure. Br J Anaesth 1987; 59: 1004-10.

18 Orko R, Heino A, Björksten F, Scheinin B, Rosenberg $P H$. Comparison of atracurium and vecuronium in anaesthesia for renal transplantation. Acta Anaesthesiol Scand 1987; 31: 450-3.

19 Hedges LV, Olkin I. Statistical Methods for Meta-analysis. London: Academic Press, 1985: 107-45.

20 Lellouch J, Lazar P. Méthodes statistiques en expérimentation biologique. Paris: Médecine-Sciences Flammarion, 1989; 225-34.

21 Bevan DR, Donati F, Gyasi L, Williams A. Vecuronium in renal failure. Can Anaesth Soc J 1984; 31: 491-6.

22 Orko $R$, Heino $A$, Rosenberg $P H$. Vecuronium in patients with and without renal failure. Acta Anaesthesiol Scand 1985; 29: 326-9.

23 Agoston S, Bencini A. Human pharmacology of vecuronium bromide. Anesthésie-Réanimation, Paris: Arnette, 1983: 11-3.

24 Starsnic $M$, Goldberg ME, Ritter DE, Marr AT, Sosis $M$, Larijani $G E$. Does vecuronium accumulate in the renal transplant patient? Can J Anaesth 1989; 36: 35-9.

25 Fahey MR, Morris RB, Miller RD, Sohn YJ, Cronnelly $R$, Gencarelli $P$. Clinical pharmacology of ORG NC45 (Norcuron(10): a new nondepolarizing muscle relaxant. Anesthesiology 1981; 55: 6-11.

26 Fisher DM, Rosen JI. A pharmacokinetic explanation for increasing recovery time following larger or repeated doses of non depolarizing muscle relaxant. Anesthesiology 1986; 65: 286-91.

27 Khuenl-Brady KS, Scharz S, Richardson FJ, Mitterschiffthaler $G$. Maintenance of surgical muscle relaxation by repeat doses of vecuronium and atracurium at three different dose levels. Eur J Anaesthesiol 1991; 8: 1-6.

28 Lee C, Katz RL. Neuromuscular pharmacology: a clinical update and commentary. Br J Anaesth 1980; 52: 173-88.

29 Cooper RA, Mirakhur RK, Elliot P, McCarthy GJ. Estimation of the potency of ORG 9426 using two different modes of nerve stimulation. Can J Anaesth 1992; 39: 139-42.

30 Kopman $A F$. The relationship of evoked electromyographic and mechanical responses following atracurium in humans. Anesthesiology 1985; 63: 208-11.

31 Carter JA, Arnold R, Yate PM, Flynn PJ. Assessment of the Datex Relaxograph during anaesthesia and atracurium- induced neuromuscular blockade. $\mathrm{Br} \mathrm{J}$ Anaesth 1986; 58 : 1447-52.

32 Dupuis JY, Martin R, Tétrault JP. Clinical, electrical and mechanical correlations during recovery from neuromuscular blockade with vecuronium. Can J Anaesth 1990; 2: 192-6.

33 Engbaek J, Ostergaard D, Viby-Mogensen J, Skovgaard Lt. Clinical recovery and train-of-four ratio measured mechanically and electromyographically following atracurium. Anesthesiology 1989; 71: 391-5.

34 Engbaek $J$. Measurement and monitoring of neuromuscular transmission. Current Opinion in Anaesthesiology 1990; 3: 625-9.

35 Lebrault C, Roure P, Strumza P, Duvaldestin P. Pharmacocinétique du vécuronium. AnesthésieRéanimation, Paris: Amette, 1983; 43-7.

36 Einarson TR, McGhan WF, Bootman $J L$, Sabers $D L$. Meta-analysis: quantitative integration of independant research results. Am J Hosp Pharm 1985; 42: 1957-64. 